\title{
Research on fire and ecosystem services must incorporate climate realities
}

$\mathrm{M}$ editerranean landscapes burn frequently and sometimes intensely. Likewise, environmental factors that favor fire - mild, moist winters and warm, dry summers - will continue to attract people to California in decades to come. Development pressure will simultaneously stress ecosystem services and increase vulnerabilities to fire.

For fire fighting alone, costs to taxpayers have exceeded a billion dollars in some years. Taking a "business as usual" approach to these problems, especially in light of climate change, will guarantee increasing losses on all fronts. These challenges require new science, difficult tradeoffs and creative solutions linking wildland fire and ecosystem services.

UC Agriculture and Natural Resources (ANR) scientists are in a unique position to advance such efforts. Our statewide network of ANR campus, regional and county scientists is advancing understanding of California landscapes and fire weather patterns. They have extensive connections to those who manage and rely on working landscapes. With on-the-ground expertise across the state, ANR's research and extension faculty can help predict and control fire, working at the crossroads between basic research and its application, to quantify and maintain ecosystem services in a changing physical and political environment.

Ecosystem services describe the multiple ways in which the environment interacts positively with human needs, and they have increasingly been the focus of science and management. Understanding, predicting and controlling how a growing human population interacts with a changing environment is a central goal for ANR's Sustainable Natural Ecosystems Strategic Initiative, and it was the focus of a conference last month (http://ucanr.org/sites/SNE).

There are four broad categories of ecosystem services: provisioning (food, water and forage), regulating (carbon sequestration and climate regulation), supporting (nutrient cycling, soil protection and pollination) and cultural (recreation and esthetics). Predicting ecosystem services requires understanding of how they function and the effects of management on ecosystem processes. Many ecosystem services are tightly linked to particular regions, landscapes, and plant and animal community types, and their spatial patterns.

Wildland fires have different effects on ecosystem services in differing landscapes. For example, wildfire effects on carbon sequestration (removal of carbon from the atmosphere and its storage in carbon sinks such as forests) vary according to ecosystem type. Grasslands are spatially extensive, often grazed by livestock; they burn frequently, and most of their potential for long-term carbon storage is in soil. Forests can store larger quantities of carbon, much of it as wood, but are susceptible to re-emitting carbon if the wood burns. Shrublands can sequester significant quantities, but frequent and intense wildfires may limit long-term storage. Wetlands have potential for significant carbon sequestration as undecomposed

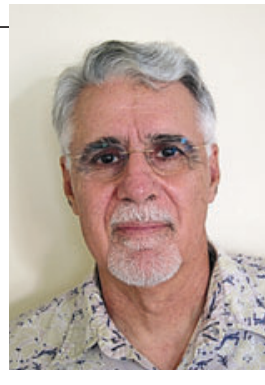

James W. Bartolome

Leader, Sustainable Natural Ecosystems Strategic Initiative, UC ANR

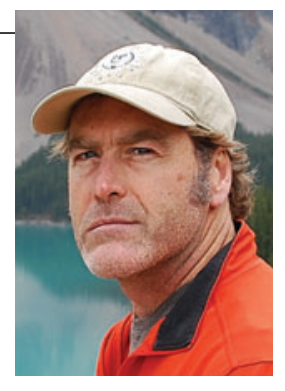

Max A. Moritz

UC Cooperative Extension Specialist, Wildland Fire, Berkeley organic material, but they are small and vulnerable to carbon loss if the moisture regime changes.

The relationship of management to carbon sequestration is also highly variable. In grassland systems, grazing management appears to have little effect on the carbon balance, whereas in forests specific activities such as fuel management can change carbon significantly. For example, in many mid-elevation forests that prehistorically burned in relatively frequent and low-intensity fires, a common management goal is to remove surface and "ladder" fuels that encourage stand-replacing crown fires. Such fuel treatments, even if done to avoid emissions, often serve multiple goals, including lowering fire hazards around communities and restoring habitat. In contrast, on shrubland landscapes where the majority of Californians live, the specific location and microclimate may be more important than management, as severe fire weather can overwhelm other factors.

By the same logic, fire affects the air we breathe and the water we drink, depending on the landscape. Although fire influences all ecosystem services, we tend to address them in isolation - and worse yet - reactively. New, regionally directed knowledge is needed to better understand how they are linked and altered by fire regimes, as well as what future shifts are likely under climate change scenarios.

Factoring in human development patterns and their associated impacts on both fire and ecosystem services is crucial, as is projecting the possible impacts of invasive species. We need new approaches to integrate the latest research into policy for adoption by political entities. Constraints posed by California's economic and political realities make identifying and pursuing long-term solutions difficult, even when science indicates proactive and sustainable paths.

Fortunately, California tends to lead rather than follow when it comes to addressing environmental challenges. Linkages between fire and ecosystem services may be complex, but they affect too many lives and valuable natural resources to allow a passive approach and could serve as a model for landscape-level, multidisciplinary problem solving. Approaches may include new academic positions in emerging interdisciplinary areas such as land-change science, sustained funding for innovative research and demonstration projects, and outreach and coordination among the public and private sectors. Investment in this research will pay off many times over, strengthening ANR's connections to California citizens, and to those who manage and rely on working landscapes. 